\title{
MULTINATIONAL COMPANIES IN LEBANON: STANDARDIZED OR LOCALIZED PERFORMANCE APPRAISAL PRACTICES?
}

\author{
Samer Francois Nakhle, Azm University, Lebanon \\ Cynthia El Fakhouri, University of Balamand, Lebanon \\ Rihab Roufael, University of Balamand, Lebanon \\ Salma Monla, University of Balamand, Lebanon
}

dx.doi.org/10.18374/IJBS-17-2.10

\begin{abstract}
Performance appraisal (PA) is a method used by companies to evaluate their employees, usually annually or semi-annually. Subsidiaries of multinational companies (MNCs) operating worldwide can either have their performance appraisal practices standardized, or localized to fit the country in which they are functioning. There are various MNC subsidiaries established in Lebanon, and this study aimed to analyze whether or not PA practices in those subsidiaries are standardized or localized. Ten MNCs' representatives were interviewed, with 5 MNCs being hotel chains, and the other 5 being accounting and consultancy firms. Semi-structured interviews were used with the ten surveys. Qualitative analysis showed that all MNCs subsidiaries interviewed applied standardization of PA practices, and that culture, managerial attitudes, and Lebanese labor law are all factors that affect the process of standardization versus localization of PA practices. The results show that MNCs in Lebanon are oriented more into standardization except when this standardization violates the labor law. Even complying with the labor law is often limited to the superficial wording rather than to the core process.
\end{abstract}

Keywords: performance appraisal, multinational companies, transfer process, standardization adaptation. 